\title{
Thrombospondin 1 is a key mediator of transforming growth factor $\beta$-mediated cell contractility in systemic sclerosis via a mitogen-activated protein kinase kinase (MEK)/extracellular signal-regulated kinase (ERK)-dependent mechanism
}

\author{
Yunliang Chen ${ }^{1+}$, Andrew Leask ${ }^{2+}$, David J Abraham ${ }^{3+}$, Laura Kennedy², Xu Shi-wen ${ }^{3}$, Christopher P Denton ${ }^{3}$, \\ Carol M Black ${ }^{3}$, Liaquat S Verjee ${ }^{4}$ and Mark Eastwood ${ }^{1 *}$
}

\begin{abstract}
Background: The mechanism underlying the ability of fibroblasts to contract a collagen gel matrix is largely unknown. Fibroblasts from scarred (lesional) areas of patients with the fibrotic disease scleroderma show enhanced ability to contract collagen relative to healthy fibroblasts. Thrombospondin 1 (TSP1), an activator of latent transforming growth factor (TGF) $\beta$, is overexpressed by scleroderma fibroblasts. In this report we investigate whether activation of latent TGF $\beta$ by TSP1 plays a key role in matrix contraction by normal and scleroderma fibroblasts.

Methods: We use the fibroblast populated collagen lattices (FPCL) model of matrix contraction to show that interfering with TSP1/TGF $\beta$ binding and knockdown of TSP1 expression suppressed the contractile ability of normal and scleroderma fibroblasts basally and in response to TGF $\beta$. Previously, we have shown that ras/mitogen-activated protein kinase kinase (MEK)/extracellular signal-regulated kinase (ERK) mediates matrix contraction basally and in response to TGF $\beta$.

Results: During mechanical stimulation in the FPCL system, using a multistation tensioning-culture force monitor (mst-CFM), TSP1 expression and p-ERK activation in fibroblasts are enhanced. Inhibiting TSP1 activity reduced the elevated activation of MEK/ERK and expression of key fibrogenic proteins. TSP1 also blocked platelet-derived growth factor (PDGF)-induced contractile activity and MEK/ERK activation.
\end{abstract}

Conclusions: TSP1 is a key mediator of matrix contraction of normal and systemic sclerosis fibroblasts, via MEK/ERK.

\section{Background}

Scleroderma (systemic sclerosis (SSc)) is a chronic disease of unknown aetiology characterised by microvascular injury, autoimmune inflammatory responses, and severe and often progressive fibrosis [1-3]. There is no therapy for the fibrosis observed in SSc. SSc dermal fibroblasts can be isolated and cultured readily, and will

\footnotetext{
* Correspondence: eastwood@wmin.ac.uk

+ Contributed equally

${ }^{1}$ School of Life Sciences, University of Westminster, London, UK

Full list of author information is available at the end of the article
}

retain their enhanced expression of type I collagen and $\alpha$ smooth muscle actin, ( $\alpha$-SMA) [4-7]. Thus, examination of the molecular difference that may exist between normal fibroblasts from healthy individuals and fibroblasts from 'lesional' areas of SSc patients would seem to be an ideal system to yield valuable insights into the pathogenesis of SSc. Although the molecular basis for SSc is unclear, we have previously shown that fibroblast from scarred (lesional) area of SSc patients show elevated constitutive extracellular signal-regulated kinase (ERK) activation and overexpress a cohort of profibrotic 
genes including connective tissue growth factor (CTGF, also known as CCN2), and the heparan sulfate containing proteoglycans (HSPGs) syndecan 2 and syndecan 4 $[7,8]$. As one of the extracellular modular glycoproteins, thrombospondin (TSP)1 was also found to be highly expressed in SSc dermal fibroblasts [9]. Significantly, whereas non-lesional and lesional SSc fibroblasts produce similar amounts of type I collagen, lesional SSc fibroblasts show markedly enhanced abilities to adhere to and contract extracellular matrix [7]. The enhanced contractile ability of lesional SSc fibroblasts was suppressed by blocking HSPG biosynthesis, mitogenactivated protein kinase kinase (MEK) or antagonising transforming growth factor (TGF) $\beta$ receptor type I (activin-linked kinase 5 (ALK5)) [7,10]. Enhanced activation of ERK was also observed in lesional SSc [7]. Moreover, heparan sulfate-dependent ERK activation contributes to the overexpression of profibrotic proteins and the enhanced contraction by lesional dermal scleroderma fibroblasts of their extracellular matrix [11]. We have begun to dissect the role that individual proteins play in fibroblast activation; for example, the HSPG syndecan 4 is required both for basal and growth factorinduced ERK activation in normal fibroblasts and for the enhanced activation of ERK observed in lesional SSc fibroblasts [7]. However, overall, the fundamental roles of individual matrix proteins in SSc pathogenesis are largely unknown.

TGF $\beta$ has long been hypothesised to be a major contributor to pathological fibrotic diseases. As TGF $\beta$ induces fibroblasts to synthesise and contract the extracellular matrix (ECM), this cytokine has long been believed to be a central mediator in wound healing and fibrotic responses, including SSc [12]. Despite the fact that enhanced ECM contraction and adhesion observed in SSc fibroblasts depends on TGF $\beta$ type I receptor (ALK5) activity, the fundamental mechanism underlying the contribution of TGF $\beta$ to the fibrotic phenotype of SSc is unclear as, in this cell type, ALK5 inhibition was unable to reduce critical features of the myofibroblast phenotype, such as $\alpha$-SMA expression and stress fibre formation [10]. The majority of the studies conducted thus far has measured acute responses to TGF $\beta$ and suggest that TGF $\beta$ alone is insufficient for sustained fibrogenic responses [12,13]. Recently, we have shown that TGF $\beta$ signalling partially contributes to the fibrotic phenotype of SSc fibroblasts, resulting from an exaggeration of processes normally operating in cells $[7,10]$. However, so far relatively little is known about the underlying cause of this exaggerated TGF $\beta$ signalling and how this might contribute to the enhanced contractile activity of SSc lesional fibroblasts.

TSP1, an extracellular modular glycoprotein secreted by many cell types, is a component of the extracellular matrix in remodelling tissues and can bind to different matrix proteins and cell surface receptors, including proteoglycans, non-integrin, and integrin receptors [14]. The latter include $\alpha 3 \beta 1$ and $\alpha 5 \beta 3$ integrin receptors [15]. TSP1 also interacts with structural proteins such as collagens, fibronectin, and laminins. These interactions may present TSP1 to the cell surface, where it can mediate interactions between these proteins and their receptors [14]. These abilities account for multifunctional nature and sometimes contradictory functions of TSP1, which include influencing platelet function, angiogenesis, tumour biology, wound healing, and vascular disease [16]. TSP1 may execute many of its functions through its ability to activate TGF $\beta$ in vitro and in vivo. TSP1 binds the latency-associated peptide (LAP) of the latent TGF $\beta$ complex. Thrombospondin-LAP complex formation involves the activation sequence of thrombospondin 1 (KRFK) and a sequence (LSKL) near the $\mathrm{N}$-terminus of LAP that is conserved in TGF $\beta$ [1-5]. The interactions of LAP with TSP1 through the LSKL and KRFK sequences are important for thrombospondin-mediated activation of latent TGF $\beta$, since LSKL peptides competitively inhibit latent TGF $\beta$ activation by TSP1 or other KRFK-containing peptides [17]. Providing evidence of functional relevance of these observations to fibrotic diseases, such as SSc, recombinant TSP1 promotes fibroblast-mediated floating collagen gel contraction induced by TGF $\beta$ [18].

Consequently, much interest exists, from both clinical and pharmaceutical points of view, in identifying not only whether TSP1 can promote the pathogenesis of fibrotic diseases such SSc, but also whether targeting TGF $\beta$ signalling by antagonising TSP1 might be useful for treating these disorders. In this study, we hypothesised that TSP1 may be an endogenous activator of TGF $\beta$ during contraction of extracellular matrix in normal and SSc fibroblasts. We used the fibroblast populated collagen lattices (FPCL) system of matrix contraction to evaluate the contribution of TSP1 to the contractile activity of normal and SSc fibroblasts both basally and in response to TGF $\beta$. We show that using TSP1 blocking peptide, or small interfering (siRNA) recognising TSP1, affects the contractile activity of normal and SSc fibroblasts. Our results provide novel insights into the underlying mechanisms behind matrix contraction by fibroblasts and the exaggerated TGF $\beta$ signalling observed in the pathogenesis of SSc.

\section{Methods \\ Cell culture}

Briefly, cell culture was performed as previously described $[19,20]$. Dermal fibroblasts from lesional (clinically affected) areas of female patients with diffuse SSc (duration of between 12 and 18 months) and 
normal individuals were taken from biopsies of age, sex and anatomically site-matched volunteers, after informed consent and ethical approval was obtained. All patients fulfilled the criteria of the American College of Rheumatology for the diagnosis of diffuse SSc, as defined by LeRoy et al. [21]. Fibroblasts were maintained in Dulbecco's modified Eagle medium (DMEM) (First Link, Birmingham, UK), 10\% foetal bovine serum (First Link, Birmingham, UK), $100 \mathrm{U} / \mathrm{ml}$ penicillin, and $100 \mathrm{mg} / \mathrm{ml}$ streptomycin, 5\% $\mathrm{CO}_{2}$. Fibroblasts were subcultured 1:4 at confluence. When appropriate, TSP1 blocking peptides (LSKL and an inert control peptide SLLK), ERK inhibitor U0126 (10 $\mu \mathrm{M}$, Promega), the ALK5 inhibitor SB 431542 (10 $\mu \mathrm{M}$, Tocris, Bristol, UK), platelet-derived growth factor (PDGF) receptor inhibitor Gleevec (2 mM, imatinib mesylate), or interferon (IFN) $\beta$ (5 ng/ml, Serono Pharmaceutical Research Institute, Geneva, Switzerland) was added.

\section{Western blot and immunofluorescence analysis}

Fibroblasts within three-dimensional collagen matrices following FPCL contraction or fibroblasts from monolayer culture were collected and lysed with $8 \mathrm{M}$ urea and 1\% SDS sample buffer. Proteins were quantified (Bradford, Bio-Rad, Hercules, California, USA), and equal amounts of protein $(25 \mu \mathrm{g})$ were subjected to SDS/PAGE using $4 \%$ to $12 \%$ polyacrylamide gels (Invitrogen, Paisley, UK). Gels were blotted onto nitrocellulose, and proteins were detected using anti-CCN2 (Santa Cruz, Wembly, UK), anti $\alpha$-SMA (Sigma, St Louis USA), anti-syndecan 4 , anti- $\alpha 3$ and anti- $\beta 5$ integrin (Zymed, Paisley, UK), anti-thrombospondin 1 (TSP1) (Abcam, Cambridge, UK), anti $\alpha$-SMA (Sigma, St Louis USA), anti p-SMAD3 (Cell Signalling, Paisley UK) and appropriate horseradish peroxidase (HRP)-conjugated secondary antibodies (Cell Signalling, Paisley UK) and an enhanced chemiluminescence (ECL) kit (Amersham, Little Chalfont, UK). Densitometry was performed using Quantity One software (Bio-Rad, Hercules, California, USA ). For immunofluorescence detection, cells were fixed in 3\% paraformaldehyde (15 $\mathrm{min}$ ) and localisation of proteins was detected as previously described [7].

\section{Real-time PCR}

Cells were serum-starved for $24 \mathrm{~h}$ and treated with or without inhibitors, as indicated, for an additional $24 \mathrm{~h}$. Total RNA was isolated using Trizol (Invitrogen Paisley, UK, and the integrity of the RNA was verified by Agilent bioanalyser. Total RNA (25 ng) was reverse transcribed and amplified using TaqMan One-step master mix and Assays on Demand primers (Applied Biosystems, Carlsbed, California, USA) in $15 \mu$ l reaction volumes with 6-carboxyfluorescein labelled TaqMan MG probe. Signals were detected using the ABI Prism
7900 HT sequence detector (Perkin-Elmer-Cetus, Vaudreuil, Canada). Triplicate samples were run, transcripts, and expression values were standardised to values obtained with control 28S RNA primers as previously described using the $\Delta \mathrm{Ct}$ method [22].

\section{FPCL}

Measurement of contractile force generated within a three-dimensional, tethered floating fibroblast-populated collagen lattice was performed as described previously [23,24]. Using $1 \times 10^{6}$ cells $/ \mathrm{ml}$ of collagen gel (First Link, Birmingham, USA), we measured the force generated across the collagen lattice with a culture force monitor (CFM). This instrument measures the minute forces exerted by cells within a collagen lattice over $24 \mathrm{~h}$ as fibroblasts attach, spread, migrate and differentiate into myofibroblasts [25]. In brief, a rectangular fibroblast seeded collagen gel was cast and floated in medium with $10 \%$ fetal calf serum (FCS), or in $2 \%$ FCS when the effect of antagonising TGF $\beta$ was examined. The collagen gels were tethered to two flotation bars on either side of the long edges, and, in turn attached to a ground point at one end and a force transducer at the other. Cell-generated tensional forces in the collagen gel were detected by the force transducer and logged into a personal computer. Graphical readings were produced every $15 \mathrm{~s}$ providing a continuous measurement of force (Dynes: $1 \times 10^{-5} \mathrm{~N}$ ) generated [25].

Mechanical stimulation of both normal and SSc fibroblasts was achieved with the use of the multistation tensioning-culture force monitor (mst-CFM) using this system FPCLs were prepared as previously described, placed into the mst-CFM and allowed to contract endogenously for $12 \mathrm{~h}$ prior to a further $12 \mathrm{~h}$ of mechanical stimulation as previously described [26]. The cells used in these experiments were passage matched; all control and inhibition experiments were run in parallel.

\section{Floating collagen gel contraction assay}

Experiments were performed essentially as described previously [7]. Briefly, 24-well tissue culture plates were precoated with bovine serum albumin (BSA). Normal and SSc lesional fibroblasts were treated with TGF $\beta$ or PDGF with or without ERK inhibitor U0126 (10 $\mu \mathrm{M}$, Promega, Madison, Winsconsin, USA), the ALK5 inhibitor SB $431542(10 \mu \mathrm{M}$, Tocris, Bristol, UK), the PDGF receptor inhibitor Gleevec (2 $\mathrm{mM}$, imatinib mesylate), or IFN $\beta$ ( $5 \mathrm{ng} / \mathrm{ml}$, Serono Pharmaceutical Research Institute SA, Geneva, Switzerland) for $24 \mathrm{~h}$. Pretreated fibroblasts were suspended in MCDB medium (Sigma, Paisley UK) and mixed with collagen solution (one part 0.2 M N-2-hydroxyethylpiperazine-N'-2-ethanesulfonic acid (HEPES), pH 8.0, four parts collagen (Vitrogen-100, $3 \mathrm{mg} / \mathrm{ml}$ ) and five parts of $\mathrm{MCDB} \times 2$ ), yielding a final 
concentration of 80,000 cells per $\mathrm{ml}$ and $1.2 \mathrm{mg} / \mathrm{ml}$ collagen. Collagen/cell suspension $(1 \mathrm{ml})$ was added to each well. After polymerisation, gels were detached from wells by adding $1 \mathrm{ml}$ of MCDB medium with PDGF, TGF $\beta$ or tumour necrosis factor (TNF) $\beta$. Contraction of the gel was quantified by loss of gel weight and decrease in gel diameter over a 24-h time period.

\section{siRNA knockdown}

Specific siRNA recognising TSP1 was purchased as a pool of three predesigned siRNAs (siRNA\#138861, siRNA\#12934 and siRNA\#12845) alone with a recommended control siRNA (Ambion, Warrington, UK). Normal and SSc fibroblasts were transfected using Silencer siRNA Transfection II Kit (Ambion, Applied Biosystems, Warrington UK). Cells were transfected either with control siRNA or control siRNA with TSP1 siRNA. Western blot analysis with an anti-TSP1 antibody was performed to check the efficiency of the siRNA to reduce TSP1 protein expression. The contractile ability of the cells was analysed as described above.

\section{Results}

Blocking TSP1 activation of latent TGF $\beta$ with LSKL peptide decreased the enhanced contractile activity of fibrotic SSc fibroblasts

Both overexpression of TSP1 and elevated TGF $\beta$ activity can be found in SSc dermal fibroblasts $[7,9,10]$. We wanted to evaluate whether TSP1 mediates matrix contraction in fibroblasts by assessing if interfering with binding of TSP1 to TGF $\beta$ suppresses the basal and TGF $\beta$-induced contractile activity of normal or SSc fibroblasts. LSKL peptides (selective antagonists of TSP1, which specifically interfere with the ability of TSP1 to activate TGF $\beta$ ) and SLLK peptide (an inert control) [27] were used in the FPCL assay of matrix contraction. Fibroblasts in the three-dimensional FPCL system generate contractile forces, similar those found in scars and in granulation tissue undergoing matrix remodelling during normal and pathological situations $[23,24,28]$. Healthy and SSc fibroblasts were pretreated with TSP1 blocking peptides (LSKL) or control peptide (SLLK) for 5 days and then transferred to a culture force monitor (CFM) and forces exerted by cells within the collagen lattice over $24 \mathrm{~h}$ in $2 \%$ serum, both in the presence and absence of added TGF $\beta$ [27] were measured and recorded. At the end of the culture period, the LSKL peptide reduced the contractile force generated by SSc fibroblasts by about $25 \%$, and also significantly blocked the TGF $\beta$-induced contractile force in both normal and SSc fibroblast groups, by $24 \%$ and $41 \%$, respectively. The LSKL peptide also showed reduced the basal contractile force generated by normal fibroblasts by approximately $14 \%$ (Figure 1 ). These

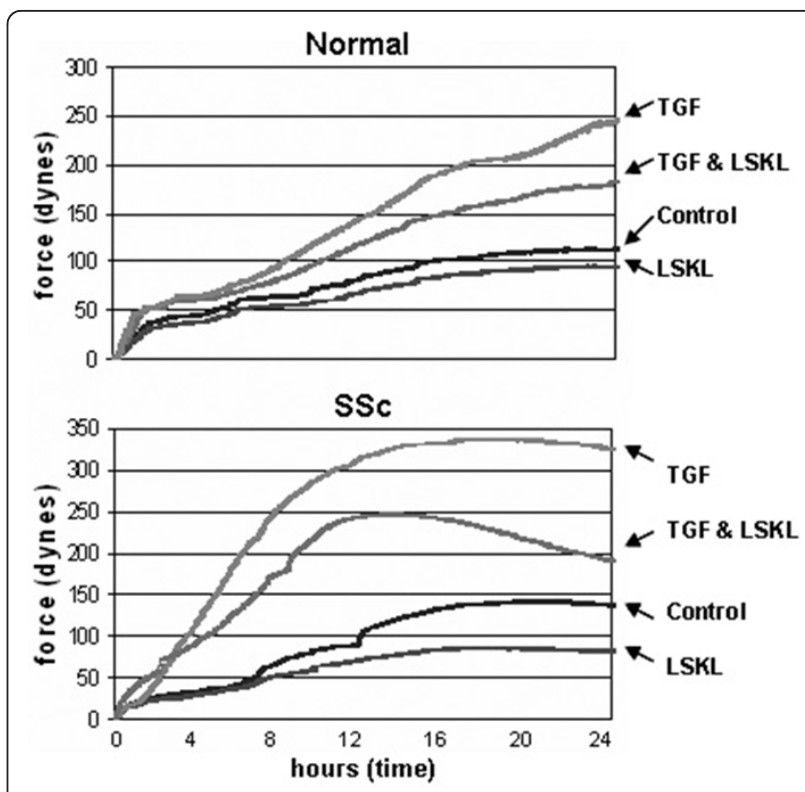

Figure 1 The enhanced contractile activity of fibrotic systemic sclerosis (SSc) fibroblasts can be moderated by blocking thrombospondin 1 (TSP1) activation of latent transforming growth factor (TGF) $\beta$ with a LSKL peptide. Normal and SSC fibroblasts were pretreated for 5 days with LSKL peptide, a selective antagonist of TSP1. Cells were then suspended in a collage lattice prior to contraction in the culture force monitor (CFM). Blocking the TSP1 function with the LSKL peptide reduced the force generated by both normal and SSc cells even after treatment with TGF $\beta$. Note that LSKL peptide also reduced the basal contractile force in normal fibroblasts groups. SLLK peptide was used as an inert control.

results suggested the intriguing notion that activation of endogenous latent TGF $\beta$ played a key role in ECM contraction by both healthy and fibrotic fibroblasts.

\section{Blocking TSP1 activation of TGF $\beta$ with LSKL peptide} impacted on the mitogen-activated protein kinase (MAPK) signalling pathways and reduced matrix protein expressions in SSc fibroblasts

Lesional dermal SSc fibroblasts are characterised by the markedly enhanced ability to adhere to and contract extracellular matrix [7]. To further investigate the mechanism underlying TSP1-dependent contractile activity, fibroblasts in fully contracted FPCL gel samples (that is, $24 \mathrm{~h}$ post culturing in the FPCL system) were analysed by western blotting to evaluate whether in this context TSP1 blocking peptide reduced expression of matrix proteins and the activation of procontractile signalling pathways. Western blot analysis revealed that the TSP1 blocking peptide reduced expression of profibrotic proteins such as $\alpha$-SMA, integrin $\alpha 3$, integrin $\beta 5$, and the activation of p-ERK and p-p38 kinase in SSc fibroblasts (Figure 2a). Moreover, TGF $\beta$-induced matrix gene expression and ERK and p38 phosphorylation in 


\section{(A)}

Normal

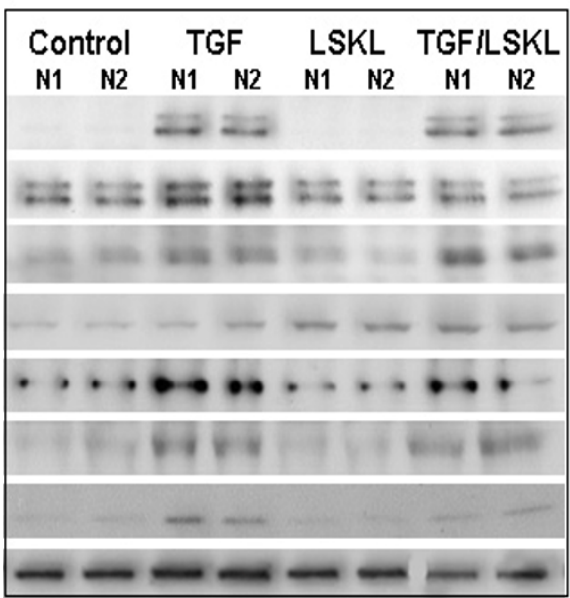

SSc

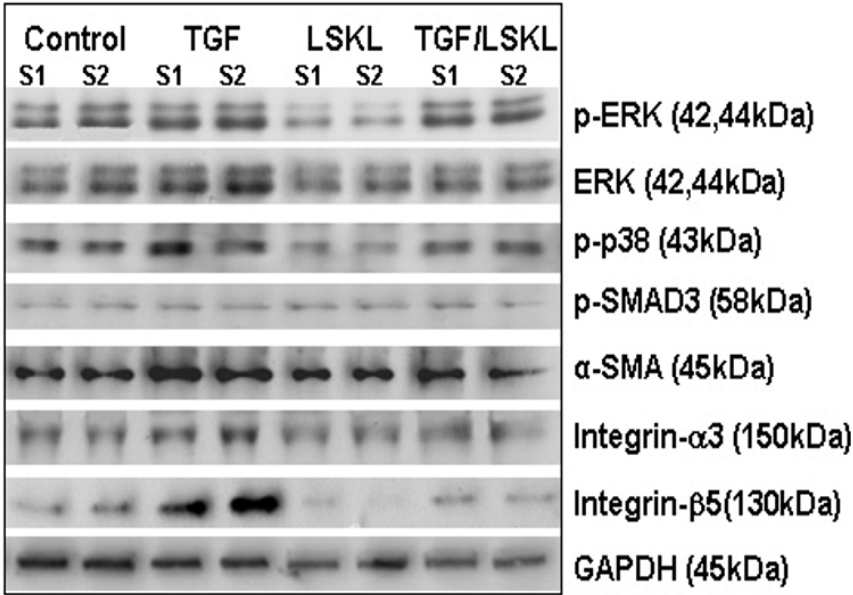

(B)

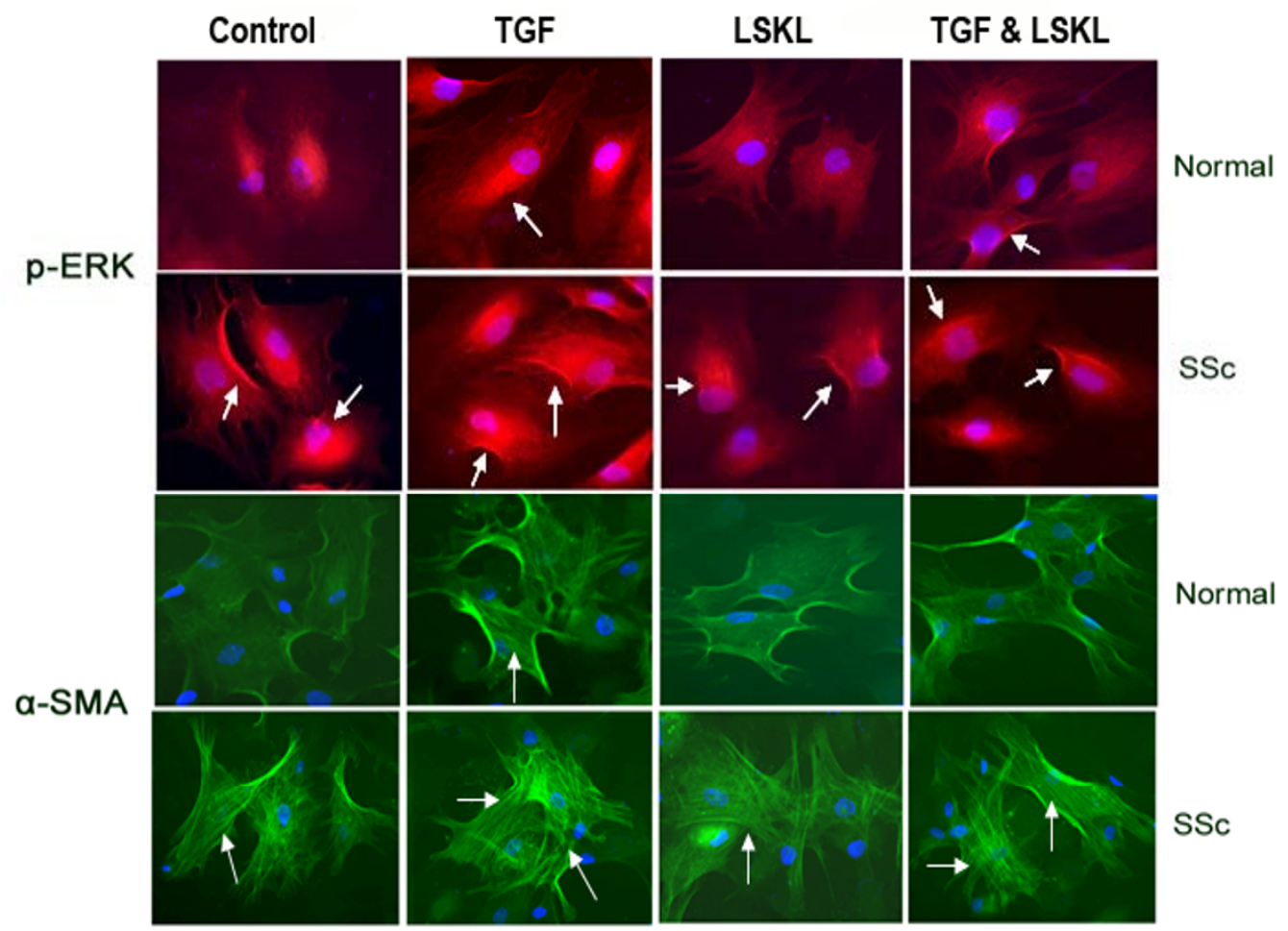

Figure 2 Blocking thrombospondin 1 (TSP1) signalling with a LSKL peptide reduces matrix protein expression in both systemic sclerosis (SSc) and normal fibroblasts. (a) Following contraction in the culture force monitor (CFM) the LSKL peptide-treated fibroblasts were prepared for western blot analyse to determine the protein expression levels. LSKL peptide reduced the expression of some profibrotic proteins and mitogen-activated protein kinase (MAPK) activities in SSc fibroblasts. (b) Immunofluorescence staining demonstrated that the LSKL peptidetreated SSC fibroblasts demonstrated a reduction in $\alpha$ smooth muscle actin ( $\alpha$-SMA) stress fibres and reduced the presence of p-extracellular signal-regulated kinase (ERK). 
both normal and SSc fibroblasts were also reduced (Figure 2a).

TGF $\beta$ causes fibroblasts to differentiate into myofibroblasts, the $\alpha$-SMA containing cells that are involve in the contraction processes in wound contraction and fibrosis tissue in vivo $[24,29,30]$. ERK activation contributes to the enhanced contraction by lesional dermal scleroderma fibroblasts by promoting the assembly of $\alpha$-SMA stress fibres [11]. To extend our data obtained by western blot analyses indicating that LSKL peptide reduced ERK activation and $\alpha$-SMA expression in SSc fibroblasts, we employed indirect immunofluorescence analysis to show that a 24-h treatment of SSc fibroblasts with LSKL peptide reduced the appearance of $\alpha$-SMA stress fibres and the intense p-ERK staining, both key features characterising SSc fibroblasts, Moreover, the LSKL peptide also blocked TGF $\beta$-induced $\alpha$-SMA expression and p-ERK activity in normal and SSc fibroblasts (Figure 2b).

\section{TSP1 is a key mediator promoting SSc fibroblast contraction}

Based on the above findings, it needed to be elucidated whether TSP1 could directly mediate the enhanced contractile activities of SSc fibroblasts. To perform this analysis, we reduced TSP1 protein expression in normal and SSc fibroblasts using siRNA recognising TSP1. Western blot analysis was used to assess the ability of siRNA recognising TSP1, compared to control siRNA, to reduce TSP1 protein expression levels (Figure $3 \mathrm{~b}$ ). The contractile ability of TSP1 knockdown cells was analysed using the CFM system. We found that the contractile ability of SSc fibroblast was reduced by $16 \%$ at the 24 th hourly time point after TSP1 expression knockdown; in addition, TGF $\beta$-induced contractility of both normal and SSc fibroblasts were diminished by $18 \%$ and $29 \%$, respectively, at the 24-h time point. The basal contractility of normal fibroblasts was reduced $19 \%$ at this time point (Figure 3a). Western blot assays were also performed with fibroblasts treated with TSP1 siRNA (Figure 3b). After TSP1 knockdown in fibroblasts from normal and SSc patients, p-ERK activation was reduced, concomitant with decreased expression of integrin $\alpha 3$. Consistent with prior data using an ALK5 inhibitor [10], extremely modest reduction of $\alpha$-SMA and integrin $\beta 5$ were observed. Expression of CCN2 and syndecan 4 was not altered in normal and SSc fibroblasts confirming previous evidence that basal expression of these proteins is independent of the TGF $\beta$ pathway [11].

TSP1 expression and p-ERK activation were enhanced by the external mechanical force loading stimulation

It has been suggested that TSP1 plays a significant role in wound healing [30]. Fibroblasts loaded by biomechanical forces within the three-dimensional FPCL system remodel their matrix resulting in potent differentiation into myofibroblasts similar to that observed in wound tissue and pathological scarring [28]. As our previous data suggested that TSP1-mediated activation of TGF $\beta$ played a key role in matrix contraction by normal and fibrotic fibroblasts, we wondered if fibroblast-induced ECM contraction itself was sufficient to induce TSP1 expression. Thus, fibroblasts from normal and SSc patients were mechanically loaded to a magnitude similar to that seen in skin wounds [31-35]. During mechanical loading, cells within the FPCL system went through normal gel contraction for $12 \mathrm{~h}$, after which cyclical mechanical forces were exerted on cells controlled by a computer. Each cycle consisted of force loading for 9 min followed by a 15-min resting phase prior to unloading for an additional $9 \mathrm{~min}$ followed by a further 15-min resting phase. Cycles were repeated 15 times for an additional $12 \mathrm{~h}$ (Figure 4a). ERK activation contributes to the overexpression of fibrotic proteins and the enhanced contraction by lesional dermal scleroderma fibroblasts [11]. Therefore, after force-loaded gel contraction, TSP1 expression and p-ERK activation were assessed by western blotting. We found that TSP1 expression and p-ERK activation were significantly increased in force-loaded fibroblasts isolated from both normal individuals and SSc patients (Figure 4b). TSP1 expression is therefore regulated by contractile activity of fibroblasts within the three-dimensional FPCL model.

\section{TSP1 is induced by PDGF and TGF $\beta$ during fibroblast- mediated matrix contraction}

Our previous research had demonstrated that TGF $\beta$ enhanced contractile ability of fibroblasts partly depends on ERK activation [11]. Inhibiting the TGF $\beta$ type I (ALK5) receptor reduced the contractility of fibroblasts, but not $\alpha$-SMA expression and stress fibre formation $[7,10]$. Conversely, the PDGF/c-abl inhibitor Gleevec reduced ECM contraction and $\alpha$-SMA expression [11]. Previously, it was shown that the antifibrotic effect of interferon $\beta$ in lung fibrosis occurred via inhibiting TGF $\beta$ activation and decreasing TSP1/2 expression [36]. Our current data showed that TSP1 contributed to the ability of fibroblasts to contract matrix and phosphorylate ERK. To further confirm the relationship between MEK/ERK signalling pathway and TSP1 function on the contractile ability of fibroblasts, normal fibroblasts were treated for $24 \mathrm{~h}$ with or without TGF $\beta$ in the presence or absence of SB431542 (ALK5 inhibitor), U0126 (MEK inhibitor) or IFN $\beta$ prior to performing a floating gel contraction assay. A floating collagen gel contraction assay was used to show that TGF $\beta$-induced contractile ability was significantly reduced by IFN $\beta$ as well as SB431542 and U0126 (Figure 5a). Following floating gel contraction, the fibroblasts in floating gel samples were analysed by western blot. Our results showed that 
(A)
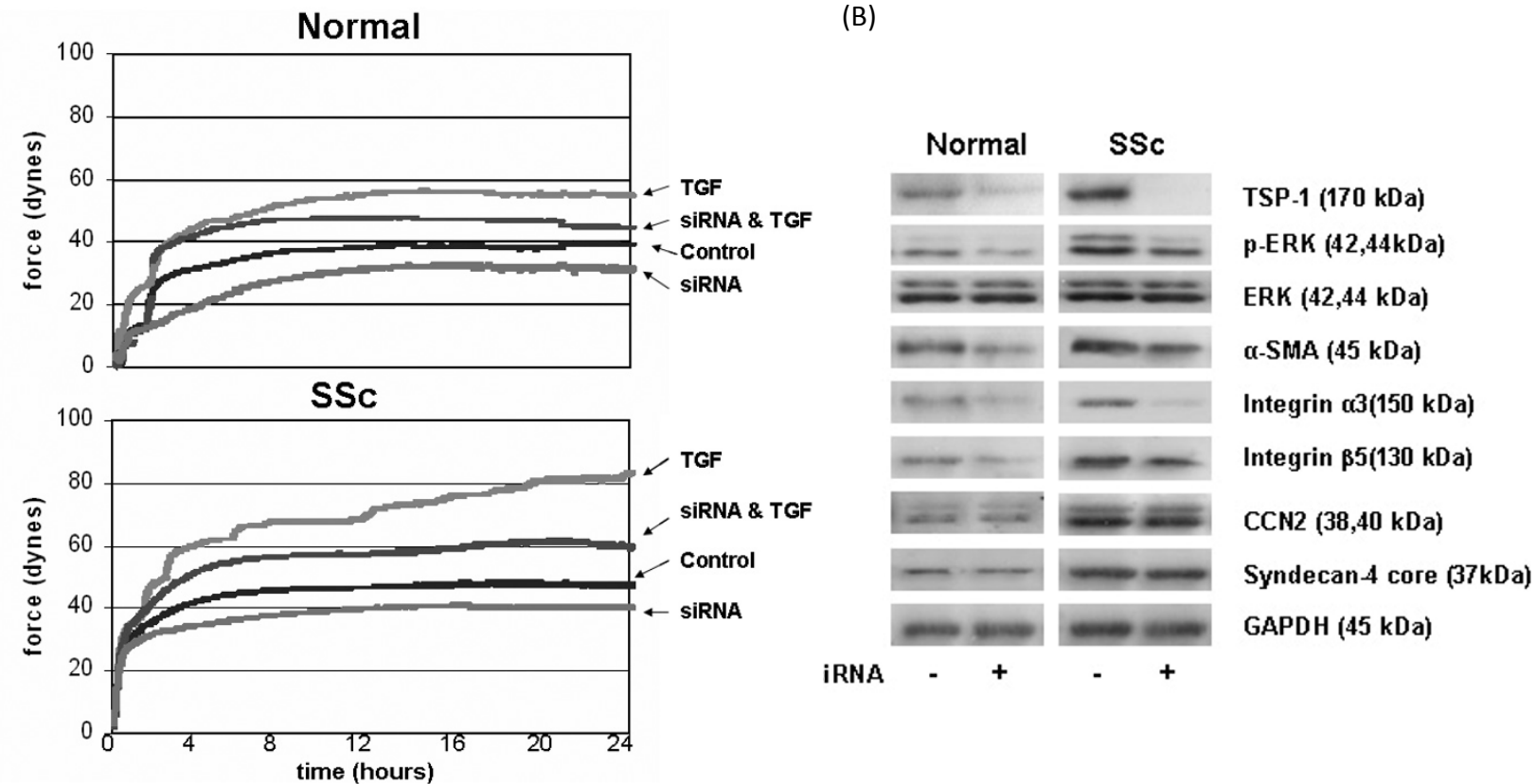

Figure 3 Knockdown thrombospondin 1 (TSP1) expression through small interfering (si)RNA transfection alters the contractile characteristics and protein expression in both normal and systemic sclerosis (SSc) fibroblasts. (a) The contractile ability of SSC and normal fibroblasts were reduced following siRNA transfection. (b) Western blot demonstrating a reduction in protein expression following siRNA transfection.

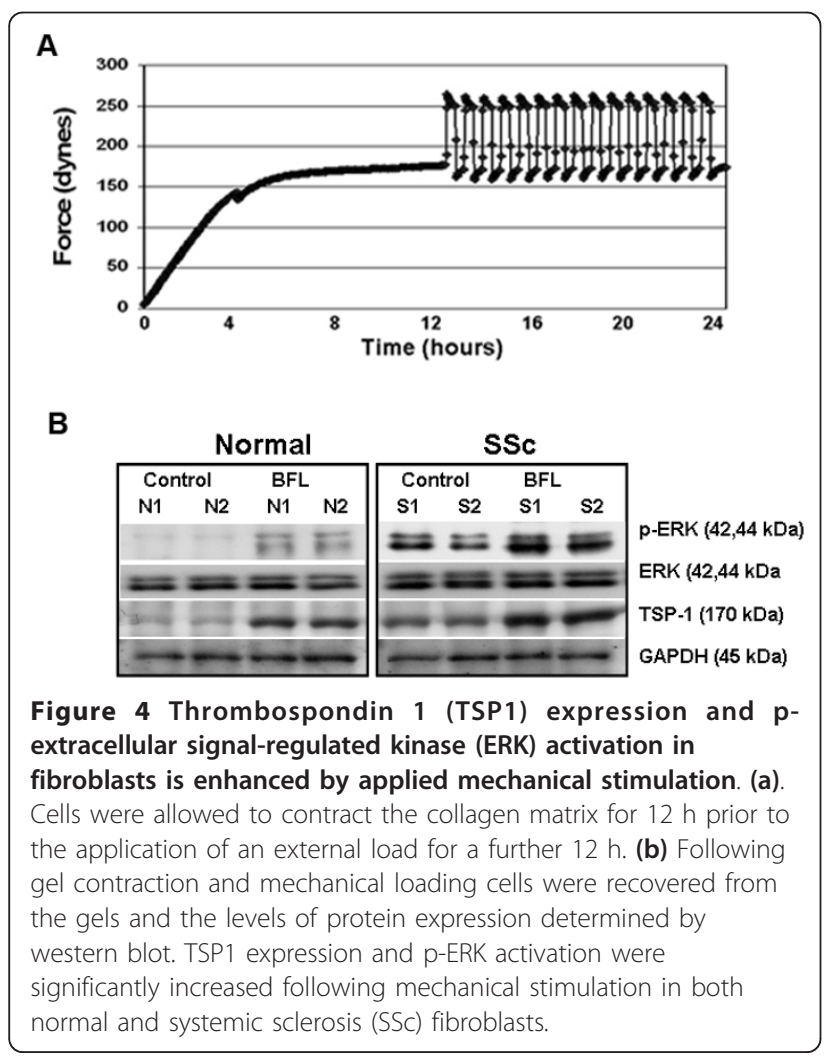

TGF $\beta$-induced TSP1 expression was inhibited by SB431542 (ALK5 inhibitor), U0126 (ERK inhibitor) or IFN $\beta$. It is interesting to note that TGF $\beta$-induced p-ERK activation also was inhibited by SB431542 and IFN $\beta$ (Figure 5b). PDGF can markedly potentiate tissue repair in vivo and also may stimulate cells to express growth factors such as TGF $\beta[36,37]$. The expression of TSP1 in vitro can be induced by platelet-derived growth factor (PDGF) [38]. Therefore, normal fibroblasts were also treated with PDGF or the PDGF receptor inhibitor Gleevec prior to conducting collagen gel contraction assays. We found that PDGFinduced contractile ability, ERK phosphorylation and TSP1 expression in a Gleevec-sensitive fashion (Figure 5a, b). Moreover, reverse transcription (RT)-PCR analysis of mRNAs extracted from fibroblasts subjected to ECM contraction revealed that the TSP1 mRNA levels were altered in a manner paralleling our TSP1 protein analyses (Figure 5c). All these results indicated that TSP1 is induced during PDGF-mediated and TGF $\beta$-mediated matrix contraction by normal fibroblasts.

Overexpression of TSP1 in SSc fibroblasts is due to endogenous TGF $\beta$ and PDGF via a MEK/ERK-dependent mechanism

Our previous work showed that TGF $\beta$ receptor type I (ALK5) and MEK/ERK contribute to the elevated 
A
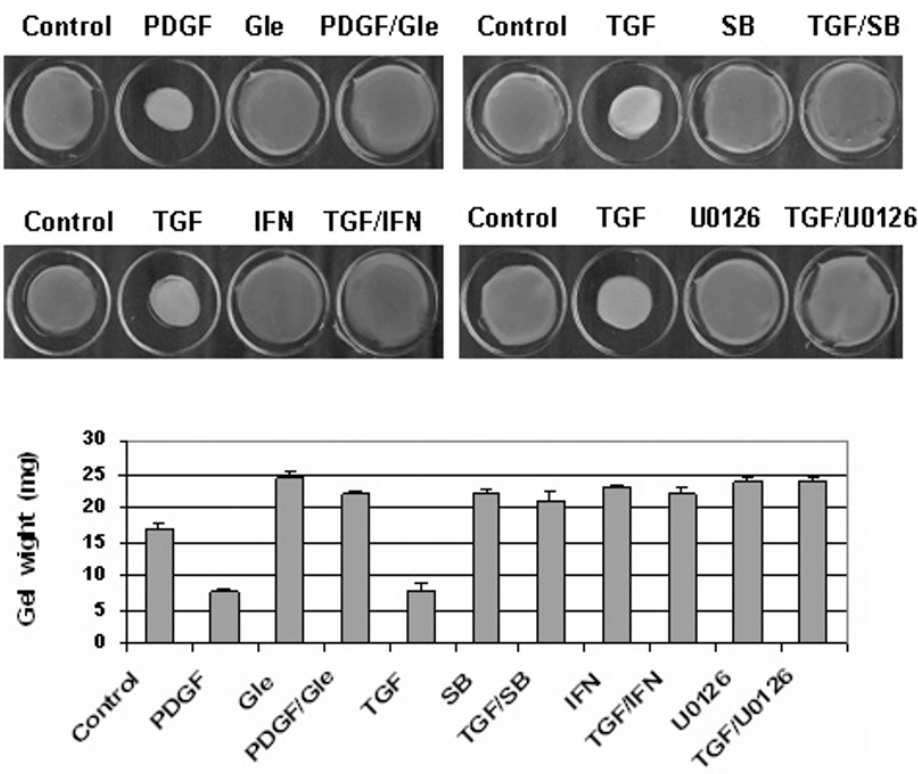

B

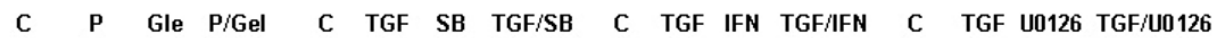

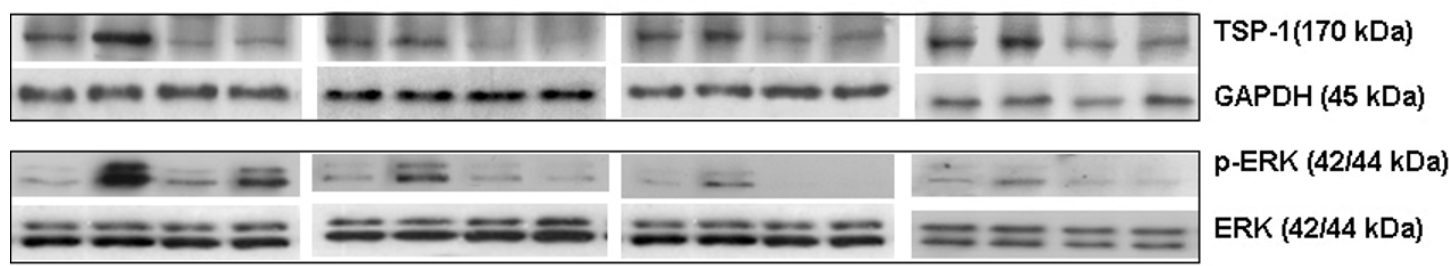

C

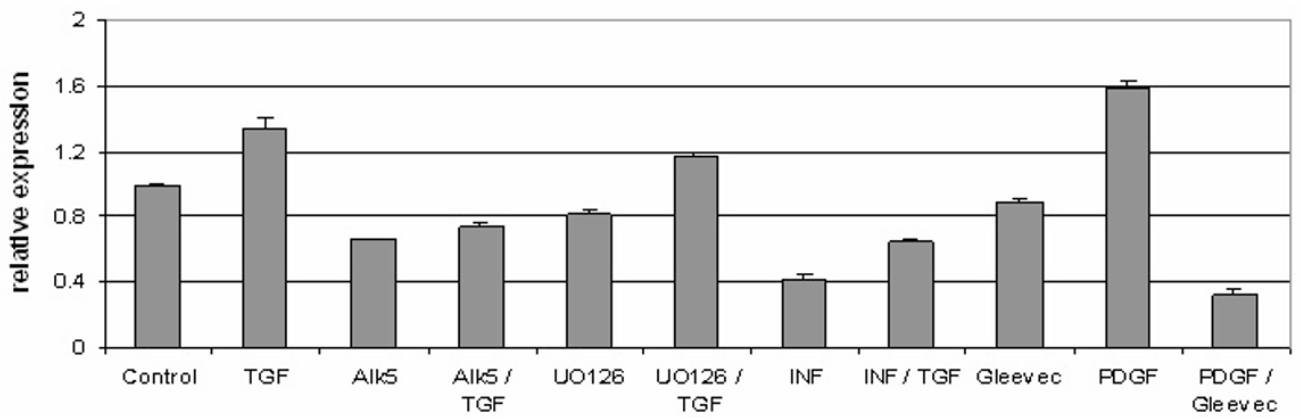

Figure 5 Thrombospondin 1 (TSP1) contributed to platelet-derived growth factor (PDGF) and transforming growth factor (TGF) $\beta$ induced contractile activation in normal fibroblasts via mitogen-activated protein kinase kinase (MEK)/extracellular signal-regulated kinase (ERK) signalling pathways. (a) Normal fibroblasts were treated overnight with or without TGF $\beta$ or PDGF, plus the antagonists of activinlinked kinase 5 (ALK5), ERK and PDGF, and interferon (IFN) $\beta$ prior to performing a floating gel contraction assay. TGF $\beta$-induced contractile ability was significantly reduced by IFN $\beta$ as that by SB431542 and U0126 in normal fibroblasts. PDGF-induced cell contractility was impaired by PDGF receptor inhibitor (Gleevec). (b) Following floating gel contraction, the fibroblasts in floating gel samples were analysed by western blotting. TGF $\beta$-induced TSP1 expression and p-ERK activations were inhibited by SB431542, U0126 or IFN $\beta$. PDGF induced the overexpression of TSP1 inhibited by Gleevec, which also accompanied a retrained reaction for PDGF-induced p-ERK activation in normal fibroblasts. (c) The mRNAs from the fibroblasts in these floating gel samples were also assayed by reverse transcription (RT)-PCR. The TSP1 gene expression levels altered in a similar manner to the TSP1 protein expression level within the corresponding groups. 
contractile abilities of SSc fibroblasts $[7,10]$. Therefore, we wanted to further clarify whether the overexpression of TSP1 in SSc fibroblasts is impacted by blocking endogenous TGF $\beta$ and PDGF signalling, SSc lesional fibroblasts were treated overnight with SB431542 (ALK5 inhibitor), U0126 (MEK inhibitor) or IFN $\beta$. TSP1 protein and mRNA expression were assayed with western blotting and RT-PCR. Our results showed that mRNA and protein expression of TSP1 in SSc fibroblasts were inhibited by antagonists of ALK5 and MEK, as well as IFN $\beta$. SSc fibroblasts treated with Gleevec also showed reduced TSP1 mRNA and protein (Figure 6). Collectively, these results indicated that the enhanced contractile ability of SSc dermal fibroblasts depends on TSP1 induction downstream of endogenous TGF $\beta$ and PDGF through MEK/ERK. Moreover, our data provide clear evidence that TSP1 plays a key role in mediating the fibrotic phenotype observed in SSc.

\section{Discussion}

The contraction processes in wound and fibrotic tissue mainly depend on a specialised form of fibroblasts known as myofibroblasts, which express the procontractile protein $\alpha$-SMA. It is also well know that a number of integrins are responsible for cell contraction within different types of cells $[39,40]$. Our previous data had found that dermal fibroblasts from SSc lesions are characterised by enhanced contractile ability of SSc fibroblasts and expression of a cohort of overexpress profibrotic genes, including $\alpha$-SMA and integrins $[7,10]$.

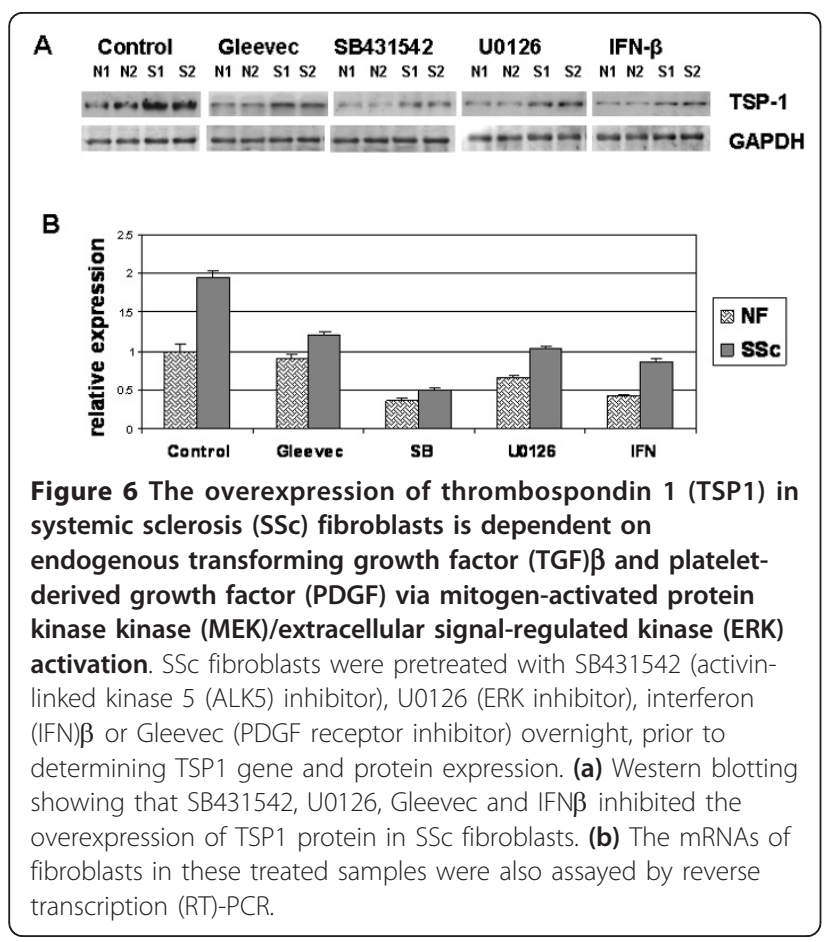

TGF $\beta 1$ is a key factor in mediating both in fibroblasts' participation in wound repair and in a promoting pathological fibrosis, including SSc. Treatment of fibroblasts with TGF $\beta$ results in their differentiation into myofibroblasts and also stimulates their production of extracellular matrix, and adhesive proteins such as integrins $[7,41]$. In monolayer culture, TGF $\beta$ is partially responsible for the phenotype of lesional SSc fibroblasts $[7,10]$. However, it remains unclear whether activation of TGF $\beta$ signalling plays a role in ECM contraction in threedimensional models of contraction. The data presented in this investigation shown that TSP1 is tightly linked with the enhanced contractility of SSc fibroblasts in the context of a three-dimensional culture system, as knockdown of the TSP1 gene or a blocking anti-TSP1 peptide, which prevents activation of latent TGF $\beta$, reduced the cell contractility of fibrotic SSc fibroblasts. In parallel, antagonising TSP1 impaired expression of $\alpha$-SMA, integrin $\alpha 3$, and integrin $\beta 5$. Blocking TSP1 expression and activity also reduced the basal contractility of normal fibroblasts. We have found that endogenous TGF $\beta$ signalling contributes to the basal contractility of normal and SSc fibroblasts in three-dimensional FPCL. The results from our current report indicate that increased activation of latent TGF $\beta$ by TSP 1 contributes to the overall activity of exogenous TGF $\beta$ during the process of ECM contraction in a three-dimensional culture. After mechanical loading of fibroblasts within the FPCL system, TGF $\beta$ activity and TSP1 expression were increased. All these results indicate that TSP1 contributes to the contractile ability of fibroblasts by promoting myofibroblast differentiation by TGF $\beta$. Our data are also consistent with the notion that TSP1 is a key mediator contributing to the enhanced contractile ability displayed by lesional SSc dermal fibroblasts. In summary, blocking TSP1 may be a viable antifibrotic strategy.

The ability of TGF $\beta 1$ to induce TSP1 in fibroblasts is ERK dependent [42]. TSP1 can also induce ERK phosphorylation via $\beta 1$ integrin [43]. Prior data from our laboratory have shown heparan sulfate-dependent ERK activation contributes to the enhanced contractile ability demonstrated by lesional dermal scleroderma fibroblasts [7]. Consistent with these results, in the current study we have shown that anti-TSP1 strategies not only reduced fibroblast contractility but also decreased ERK activation in fibroblasts subjected to ECM contraction and mechanical loading. We have also shown that TGF $\beta$ and PDGFinduced contractility in normal and SSc fibroblasts corresponded with elevated expression of TSP1 and ERK activation. It has been shown that TSP1 can bind and stabilise PDGF, enhancing the biological effect of PDGF in proliferative tissue repair [39]. It is interesting to note that the overexpression of TSP1, whether induced by TGF $\beta$ and PDGF in normal fibroblasts or basally in SSc 
lesional dermal fibroblasts, was inhibited by the MEK/ ERK inhibitor (U0126). All these results indicate that, as an endogenous activator of TGF $\beta$, TSP1 contributes to the pathological contractile activity of SSc fibroblasts. Moreover, TSP1 may also potentially mediate responses to PDGF in the pathogenesis of SSc. Our results are consistent with a previous suggestion that constitutive overexpression of TSP1 in SSc fibroblasts depends on autocrine TGF $\beta$ signalling [9].

Lesional SSc dermal fibroblasts overexpress syndecan 4 , CCN2 and TSP1 $[7,9,10]$. CCN2 is expressed by mesenchymal cells undergoing active tissue remodelling, and is characteristically overexpressed in connective tissue pathologies such as fibrosis and cancer $[6,44]$. Heparan sulfate chains of syndecan 4 mediate response to growth and differentiation factors such as TGF $\beta$ [45]. Syndecan 4 also binds CCN and acts as a coreceptor for CCN2 [46]. Although the precise nature of the interactions among syndecan $4, \mathrm{CCN} 2$ and TSP1 is still unclear, our previous investigations found low expression of TSP1 in fibroblasts isolated from syndecan 4 -/or CCN2 -/- mice $[11,47]$. In our current study, TSP1 knockdown with siRNA did not alter expression of syndecan 4 and CCN2. Collectively, these results suggest expression of TSP1 in fibroblast culture is downstream of both syndecan 4 and CCN2. It has been reported that, in a mouse model of arthritis, injection of TSP1 blocking peptides for 16 days reduced joint infiltration and inflammation and CCN2 message and protein levels [9]. However, this reduced CCN2 could result indirectly due to the ability of TSP 1 to activate latent TGF $\beta$. Alternatively, a mechanism involving activation of cell types other than fibroblasts might be involved. Therefore, whether TSP1 directly affects CCN2 expression in vivo in SSc still needs to be investigated.

We have previously shown that the ras/MEK/ERK 'classical' MAP kinase cascade is important for several features of fibrogenesis. For example, MEK/ERK mediates the induction of CCN2 expression in normal mesenchymal cells $[48,49]$. In addition, MEK/ERK is required for $\alpha$-SMA stress fibre assembly, via a syndecan 4-dependent mechanism [7,10]. Moreover, the enhanced constitutive ERK activation in lesional SSc fibroblasts is due to an increase in syndecan 4 expression $[7,10]$. The MEK-ERK pathway and HSPGs contribute to the overexpression of profibrotic proteins and enhanced contractile forces in SSc dermal fibroblasts, and the procontractile signals from TGF $\beta$ are integrated through syndecan 4 and MEK/ERK [11]. TGF $\beta$ has long been hypothesised to be a major contributor to pathological fibrotic diseases [41]. In this investigation we showed that TSP1-mediated TGF $\beta$ activation contributes to the pathological contractile activity of SSc fibroblasts via an ERK-dependent mechanism. In contrast, as a multifunctional cytokine, TGF $\beta$ is not only a key regulator of extracellular matrix assembly and remodelling but also affects a wide variety of cellular processes. Therefore, therapeutic strategies focusing on non-specific, systemic blockade of TGF $\beta$ ligandreceptor interactions may have a problematic side effect profile considering the complex function of TGF $\beta$ in vivo [41]. Conversely, TSP1 is a multicellular protein that modulates cell functions and cell-matrix interactions [50]. Abnormalities observed in TSP1-null animals resemble those observed in TGF $\beta 1$ deficient animals, but are much less severe [51]. Collectively, our results suggest that, as compared to broad targeting of TGF $\beta$, TSP1 may be an ideal therapeutic target for fibrotic diseases such as SSc.

\section{Conclusions}

In summary, in this report we provide useful information to further understand the mechanism underlying extra cellular matrix contraction by fibroblasts and exaggerated TGF $\beta$ signalling in the pathogenesis of SSc. Our results could also prove to be a great advantage as a potential therapy for disorders characterised by the enhanced activity of TGF $\beta$ in fibrotic disorders such as SSc.

\section{Acknowledgements}

This work was funded by the Raynaud's and Scleroderma Association. The multistation tensioning-culture force monitor was developed and built with funding from the Scleroderma Society. We greatly appreciate the gift of SLLK peptide from Dr Joanne E Murphy-Ullrich, University of Alabama at Birmingham, Birmingham, AL, USA.

\section{Author details}

${ }^{1}$ School of Life Sciences, University of Westminster, London, UK. ${ }^{2}$ Canadian Institute of Health Research Group in Skeletal Development and Remodelling, Division of Oral Biology and Department of Physiology and Pharmacology, Schulich School of Dentistry, University of Western Ontario, London, Ontario, Canada. ${ }^{3}$ Department of Inflammation, Centre for

Rheumatology, University College London, London, UK. ${ }^{4}$ Kennedy Institute of Rheumatology, Imperial College London, London, UK.

\section{Authors' contributions}

$Y C, A L, D J A$ and ME designed and conceived the study. YC, LK, XS, ME, DJA and $\mathrm{AL}$ performed and interpreted the experiments. CPD, CMB and LSV assisted with the experimental design and discussed the manuscript. YC, AL, DJA and ME wrote the manuscript. All authors read and approved the final manuscript.

\section{Competing interests}

The authors declare that they have no competing interests.

Received: 21 June 2010 Accepted: 31 March 2011

Published: 31 March 2011

\section{References}

1. Varga J, Abraham D: Systemic sclerosis: a prototypic multisystem fibrotic disorder. J Clin Invest 2007, 117:557-567.

2. Denton CP, Black CM, Abraham DJ: Mechanisms and consequences of fibrosis in systemic sclerosis. Nat Clin Pract Rheumatol 2006, 2:134-144.

3. Kähäri VM: Activation of dermal connective tissue in scleroderma. Ann Med 1993, 25:511-518. 
4. LeRoy C: Increased collagen synthesis by scleroderma skin fibroblasts in vitro. J Clin Invest 1974, 54:880-889.

5. Kähäri VM, Multimäki P, Vuorio E: Elevated pro alpha 2(I) collagen mRNA levels in cultured scleroderma fibroblasts result from an increased transcription rate of the corresponding gene. FEBS Lett 1987, 215:331-334.

6. Abraham DJ, Shiwen X, Black CM, Sa S, Xu Y, Leask A: Tumor necrosis factor alpha suppresses the induction of connective tissue growth factor by transforming growth factor- $\beta$ in normal and scleroderma fibroblasts. J Biol Chem 2000, 275:15220-15225.

7. Chen Y, Shi-Wen X, van Beek J, Kennedy L, McLeod M, Renzoni EA, BouGharios G, Wilcox-Adelman S, Goetinck PF, Eastwood M, Black CM, Abraham DJ, Leask A: Matrix contraction by dermal fibroblasts requires transforming growth factor- $\beta$ /activin-linked kinase 5 , heparan sulfatecontaining proteoglycans, and MEK/ERK: insights into pathological scarring in chronic fibrotic disease. Am J Pathol 2005, 167:1699-1711.

8. Shi-wen X, Pennington D, Holmes A, Leask A, Bradham D, Beauchamp JR, Fonseca C, du Bois RM, Martin GR, Black CM, Abraham DJ: Autocrine overexpression of CTGF maintains fibrosis: RDA analysis of fibrosis genes in systemic sclerosis. Exp Cell Res 2000, 259:213-224.

9. Mimura Y, Ihn H, Jinnin M, Asano Y, Yamane K, Tamaki K: Constitutive thrombospondin-1 overexpression contributes to autocrine transforming growth factor- $\beta$ signalling in cultured scleroderma fibroblasts. Am J Pathol 2005, 166:1451-1463.

10. Chen Y, Shi-wen X, Eastwood M, Black CM, Denton CP, Leask A, Abraham DJ: Contribution of activin receptor-like kinase 5 (transforming growth factor $\beta$ receptor type I) signaling to the fibrotic phenotype of scleroderma fibroblasts. Arthritis Rheum 2006, 54:1309-1316.

11. Chen Y, Leask A, Abraham DJ, Pala D, Shiwen X, Khan K, Liu S, Carter DE, Wilcox-Adelman S, Goetinck P, Denton CP, Black CM, Pitsillides AA, Sarraf CE, Eastwood M: Heparan sulfate-dependent ERK activation contributes to the overexpression of fibrotic proteins and enhanced contraction by scleroderma fibroblasts. Arthritis Rheum 2008, 58:577-585.

12. Leask A, Abraham DJ: TGF- $\beta$ signalling and the fibrotic response. FASEB J 2004, 18:816-827.

13. Mori T, Kawara S, Shinozaki M, Hayashi N, Kakinuma T, Igarashi A, Takigawa M, Nakanishi T, Takehara K: Role and interaction of connective tissue growth factor with transforming growth factor- $\beta$ in persistent fibrosis: a mouse fibrosis model. J Cell Physiol 1999, 181:153-159.

14. Bornstein P: Diversity of function is inherent in matricellular proteins: an appraisal of thrombospondin 1. J Cell Biol 1995, 130:503-506.

15. Lymn JS, Patel MK, Clunn GF, Rao SJ, Gallagher KL, Hughes AD: Thrombospondin-1 differentially induces chemotaxis and DNA synthesis of human venous smooth muscle cells at the receptor-binding level. J Cell Sci 2002, 115:4353-4360.

16. Esemuede N, Lee T, Pierre-Paul D, Sumpio BE, Gahtan V: The role of thrombospondin-1 in human disease. J Surg Res 2004, 122:135-142.

17. Ribeiro SM, Poczatek M, Schultz-Cherry S, Villain M, Murphy-Ullrich JE: The activation sequence of thrombospondin-1 interacts with the latencyassociated peptide to regulate activation of latent transforming growth factor- $\beta$. J Biol Chem 1999, 274:13586-13593.

18. Sakai K, Sumi Y, Muramatsu H, Hata K, Muramatsu T, Ueda M: Thrombospondin-1 promotes fibroblast-mediated collagen gel contraction caused by activation of latent transforming growth factor $\beta$ 1. J Dermatol Sci 2003, 31:99-109.

19. Shi-wen X, Pennington D, Holmes A, Leask A, Bradham D, Beauchamp JR, Fonseca C, du Bois RM, Martin GR, Black CM, Abraham DJ: Exp Cell Res 2000, 259:213-224

20. Abraham DJ, Shiwen X, Black CM, Sa S, Xu Y, Leask A: Tumor necrosis factor alpha suppresses the induction of connective tissue growth factor by transforming growth factor $-\beta$ in normal and scleroderma fibroblasts. J Biol Chem 2000, 275:15220-15225.

21. LeRoy EC, Black C, Fleischmajer R, Jablonska S, Krieg T, Medsger TA Jr, Rowell N, Wollheim F: Scleroderma (systemic sclerosis): classification, subsets and pathogenesis. J Rheumatol 1988, 15:202-205.

22. Shi-wen $X$, Stanton LA, Kennedy L, Pala D, Chen Y, Howat SL, Renzoni EA, Carter DE, Bou-Gharios G, Stratton RJ, Pearson JD, Beier F, Lyons KM, Black CM, Abraham DJ, Leask A: CCN2 is necessary for adhesive responses to transforming growth factor- $\beta 1$ in embryonic fibroblasts. J Biol Chem 2006, 281:10715-10726

23. Eastwood M, Porter R, Khan U, McGrouther G, Brown R: Quantitative analysis of collagen gel contractile forces generated by dermal fibroblasts and the relationship to cell morphology. J Cell Physiol 1996, 166:33-42.

24. Tomasek JJ, Gabbiani G, Hinz B, Chaponnier C, Brown RA: Myofibroblasts and mechano-regulation of connective tissue remodelling. Nat Rev Mol Cell Biol 2002, 3:349-363.

25. Eastwood M, McGrouther DA, Brown RA: A culture force monitor for measurement of contraction forces generated in human dermal fibroblast cultures: evidence for cell-matrix mechanical signalling. Biochim Biophys Acta 1994, 1201:186-192.

26. Eastwood M, Mudera VC, McGrouther DA, Brown RA: Effect of precise mechanical loading on fibroblast populated collagen lattices: morphological changes. Cell Motil Cytoskeleton 1998, 40:13-21.

27. Meek RL, Cooney SK, Flynn SD, Chouinard RF, Poczatek MH, MurphyUllrich JE, Tuttle KR: Amino acids induce indicators of response to injury in glomerular mesangial cells. Am J Physiol Renal Physiol 2003, 285:F79-86.

28. Grinnell F: Fibroblast biology in three-dimensional collagen matrices. Trends Cell Biol 2003, 13:264-269.

29. Skalli O, Gabbiani G: The biology of the myofibroblast in relationship to wound contraction and fibrocontractive disease. In The Molecular and Cellular Basis of Wound Repair. 2 edition. Edited by: Clark RAF, Henson PM. New York: Plenum Press; 1998:373-402.

30. Rudolph R, Van de Berg J, Ehrlich PH: Wound contraction and scar contracture. In Wound Healing, Biochemical and Clinical Aspects. Edited by: Cohen IK, Diegelmann RF, Lindblad WJ. Philadelphia, PA: Saunders; 1992:96-114.

31. Agah A, Kyriakides TR, Lawler J, Bornstein P: The lack of thrombospondin-1 (TSP1) dictates the course of wound healing in double-TSP1/TSP2-null mice. Am J Pathol 2002, 161:831-839.

32. Robbins JR, Evanko SP, Vogel KG: Mechanical loading and TGF- $\beta$ regulate proteoglycan synthesis in tendon. Arch Biochem Biophys 1997, 342:203-211.

33. Carlson MA, Longaker MT: The fibroblast-populated collagen matrix as a model of wound healing: a review of the evidence. Wound Repair Regen 2004, 12:134-147.

34. Grinnell F: Fibroblast-collagen-matrix contraction: growth-factor signalling and mechanical loading. Trends Cell Biol 2000, 10:362-365.

35. Prajapati RT, Chavally-Mis B, Herbage D, Eastwood M, Brown RA: Mechanical loading regulates protease production by fibroblasts in threedimensional collagen substrates. Wound Repair Regen 2000, 8:226-237.

36. Azuma A, Li YJ, Abe S, Usuki J, Matsuda K, Henmi S, Miyauchi Y, Ueda K, Izawa A, Sone $S$, Hashimoto S, Kudoh S: Interferon- $\beta$ inhibits bleomycininduced lung fibrosis by decreasing transforming growth factor- $\beta$ and thrombospondin. Am J Respir Cell Mol Biol 2005, 32:93-98.

37. Pierce GF, Mustoe TA, Lingelbach J, Masakowski VR, Griffin GL, Senior RM, Deuel TF: Platelet-derived growth factor and transforming growth factor$\beta$ enhance tissue repair activities by unique mechanisms. J Cell Biol 1989, 109:429-440.

38. Krishnaswami S, Ly QP, Rothman VL, Tuszynski GP: Thrombospondin-1 promotes proliferative healing through stabilization of PDGF. J Surg Res 2002, 107:124-130

39. Zhang ZG, Bothe I, Hirche F, Zweers M, Gullberg D, Pfitzer G, Krieg T, Eckes B, Aumailley M: Interactions of primary fibroblasts and keratinocytes with extracellular matrix proteins: contribution of $\alpha_{2} \beta 1$ integrin. J Cell Sci 2006, 119:1886-1895.

40. de Rooij J, Kerstens A, Danuser G, Schwartz MA, Waterman-Storer CM: Integrin-dependent actomyosin contraction regulates epithelial cell scattering. J Cell Biol 2005, 171:153-164.

41. Leask A: Scar wars: is TGF $\beta$ the phantom menace in scleroderma? Arthritis Res Ther 2006, 8:213.

42. Nakagawa T, Lan HY, Glushakova O, Zhu HJ, Kang DH, Schreiner GF, Böttinger EP, Johnson RJ, Sautin YY: Role of ERK1/2 and p38 mitogenactivated protein kinases in the regulation of thrombospondin-1 by TGF- $\beta 1$ in rat proximal tubular cells and mouse fibroblasts. J Am Soc Nephrol 2005, 16:899-904.

43. Wilson KE, Li Z, Kara M, Gardner KL, Roberts DD: Beta 1 integrin- and proteoglycan-mediated stimulation of T lymphoma cell adhesion and mitogen-activated protein kinase signaling by thrombospondin-1 and thrombospondin-1 peptides. J Immunol 1999, 163:3621-3628.

44. Frazier KS, Grotendorst GR: Expression of connective tissue growth factor mRNA in the fibrous stroma of mammary tumors. Int I Biochem Cell Biol 1997, 29:153-161. 
45. Fears $C Y$, Woods $A$ : The role of syndecans in disease and wound healing. Matrix Biol 2006, 25:443-456.

46. Chen Y, Abraham DJ, Shi-Wen X, Pearson JD, Black CM, Lyons KM, Leask A: CCN2 (connective tissue growth factor) promotes fibroblast adhesion to fibronectin. Mol Biol Cell 2004, 15:5635-5646.

47. Kennedy L, Liu S, Shi-Wen X, Chen Y, Eastwood M, Sabetkar M, Carter DE, Lyons KM, Black CM, Abraham DJ, Leask A: CCN2 is necessary for the function of mouse embryonic fibroblasts. Exp Cell Res 2007, 313:952-964.

48. Chen Y, Blom IE, Sa S, Goldschmeding R, Abraham DJ, Leask A: CTGF expression in mesangial cells: involvement of SMADs, MAP kinase, and PKC. Kidney Int 2002, 62:1149-1159.

49. Stratton R, Rajkumar V, Ponticos M, Nichols B, Shiwen X, Black CM, Abraham DJ, Leask A: Prostacyclin derivatives prevent the fibrotic response to TGF- $\beta$ by inhibiting the Ras/MEK/ERK pathway. FASEB J 2002, 16:1949-1951.

50. Bornstein P, Agah A, Kyriakides TR: The role of thrombospondins 1 and 2 in the regulation of cell-matrix interactions, collagen fibril formation, and the response to injury. Int J Biochem Cell Biol 2004, 36:1115-1125.

51. Crawford SE, Stellmach V, Murphy-Ullrich JE, Ribeiro SM, Lawler J, Hynes RO, Boivin GP, Bouck N: Thrombospondin-1 is a major activator of TGF- $\beta 1$ in vivo. Cell 1998, 93:1159-1170.

doi:10.1186/1755-1536-4-9

Cite this article as: Chen et al:: Thrombospondin 1 is a key mediator of transforming growth factor $\beta$-mediated cell contractility in systemic sclerosis via a mitogen-activated protein kinase kinase

(MEK)/extracellular signal-regulated kinase (ERK)-dependent mechanism. Fibrogenesis \& Tissue Repair 2011 4:9.

\section{Submit your next manuscript to BioMed Central} and take full advantage of:

- Convenient online submission

- Thorough peer review

- No space constraints or color figure charges

- Immediate publication on acceptance

- Inclusion in PubMed, CAS, Scopus and Google Scholar

- Research which is freely available for redistribution

Submit your manuscript at www.biomedcentral.com/submit 